\title{
The Contribution of Humanism to the Birth of Modern Science*
}

\author{
CESARE VASOLI
}

F or quite a long while now there has been a great deal of discussion over a complex and delicate topic: the relation between humanist cultural reform and the origins of modern science. The debate is clouded by misunderstandings and, from many a point of view, hardly adds to the positive development of historical studies. Since the time of the old revolt of the "medievalists" against the Burckhardtian concept of "Renaissance man," several scholars have let themselves be overwhelmed by the closeness or similarity of problems treated by masters who lived centuries earlier, in extremely different cultural environments. These scholars feel that at least as far as science is concerned, there are no differences or breaks between the typical ideas of scientific knowledge of late Scholasticism and those taken over and developed by the "pioneers" of the new science. They have thus failed to evaluate certain profound differences in "language," method, and logic that should have led to considerations of an exceedingly more cautious and prudent nature. Indeed, since the figure of the "humanist" became more and more bound within the framework of "studia litteraria" and linked to the strictly professional destination of teaching rhetoric, poetics, or grammatical-philological disciplines, it was not very hard to claim that the entire course of the first humanistic age had essentially been a negative period for the history of science. Indeed it had been overpowered by literary interests and greatly deviated from its logical development by persistent disputes with the "moderns" and by the violent and unjustified condemnation of logic, "physics," and the most advanced scholastic speculative techniques.

It is well known that prestigious and authoritative scholars (I am going to cite only the best-known such as Duhem, Thorndike, Sarton, Randall and A. Maier) all essentially concur in maintaining this idea. ${ }^{1}$

* This paper is a revised version of a lecture delivered at the University of Chicago, Morris Fishbein Center for the Study of the History of Science and Medicine, on October 6, 1977. Sincere thanks are expressed here to Professor Allen G. Debus for the invitation and to Professor William H. McNeill, Director of the Center. 


\section{2 / Renaissance and Reformation}

They claim that the dominant lines of "real" scientific thought can be traced, between the 14 th and 15 th centuries, right through the persisting Aristotelian tradition developed by the scholastic masters of the period who displayed great rigour and a precise awareness of the theoretical problems. Therefore, a comparison - which is not always proper and convincing - of several texts by Buridan, Albertus de Saxonia, or Marsilius of Inghen to texts by Leonardo, Galileo or Descartes has offered the possibility of drawing a rather drastic conclusion: to wit the science of mechanics is treated as a special "event" wholly detached from humanistic culture, to which also the developments in astronomy, medicine, or natural sciences remained totally foreign. With the same intention - or rather using even more biting tones - the proof that the humanists were wholly unable to grasp the more mature and important acquisitions of medieval logic (along the path to what would later lead to the great Leibnitz rebirth and the origins of "formal logic") lies in their contempt for the cavillationes, ampliationes and sophismata so developed by late scholastic masters. And it certainly has been rather easy to contrast the "simple" dialectics of the humanist scholars completely involved in the domination of "argumentation" and resolved in the construction of "topics" - to the extremely refined analyses of Paolo Veneto or other 15th-century Paduan scholars (such as Paolo della Pergola and Gaetano of Thiene). To this we must add that, regarding the never-ending dispute about the relations between literary and scientific cultures, the "sciences of man" and the "sciences of nature," the judgements regarding the historical role actually played by humanist culture have often been especially drastic and categorical. Others, reverting to a dispute which after centuries have gone by has lost all real meaning, have attempted to invert the traditional image of the Renaissance as a period of great critical importance in the historical progress of modern Europe. They have even gone so far as to formulate new historiographic classifications such as the "Counter-Renaissance" which are useful in setting up interesting long-term perspectives, but which are just as incapable of explaining the actual course of historical events.

These attitudes - which are nevertheless important since they have involved scholars in attempts to eliminate once and for all certain quadri di maniera of the two Renaissance centuries - today appear further from our need to untangle effectively the complex web of traditions and cultural innovations lying at the origin of modern science. I feel that today historians of philosophy and science are more aware of the fragility of certain overly abused distinctions. They realize that it is necessary to follow - step by step, moment by moment - the slow maturing of new methodological approaches and the growth of a critical bent, born in the field of philological studies, but soon turned 
into a different way of considering the past, ideas, discoveries, authors of Antiquity, be they writers or philosophers, jurists or theologians, historians or scientists. Actually, it is quite impossible to reconstruct the evolution of scientific thought from the 14th to the 16 th centuries without always paying heed to both the disputes over the relative superiority of the various "arts" (which often involved a clear change in the traditional structure of the forms of knowledge) and the texts in which there is present the basic contrast between late medieval culture and the intellectual experience of the studia humanitatis which more and more clearly aimed at taking over all the scientific heritage from Antiquity and putting it into a serious philological context. In fact, it is this very need which drove one of the founders of modern philology, Lorenzo Valla, to follow in the footsteps of Petrarch, Salutati, and Bruni in the controversy against the scholastic "barbarians." They were accused not only of falsifying Aristotle's genuine language but also of substituting the "easy" dialectics which make up and govern all human speech with a truly cumplicated science, an obscure, confused, and arbitrary jargon. But the most important fact is that Valla's concern was not limited solely to emphasizing the rights of eloyuentia and its function essential to scientific thought; instead he attempted to reconstruct, through an analysis and discussion of Aristotelian logic, texts and their actual linguistic roots, the ultimate foundation of a kind of method which has to be again rendered active and efficient for all the purposes man might have during his historic lifespan. Likewise, a similar approach was taken by other humanists, ranging from Guarino to Niccolŏ Leoniceno, who especially during the second half of the 15 th century deal with the writings of doctors, "physicists" and classical philosophers, either to reconstruct their real "status," or else to submit them to their contemporaries in easier, more elegant, and more comprehensible versions, and thus make them available to an ever-growing public of cultured people.

Of course, we could now go into the inevitable limits of humanistic philology; we might also take note of the fact that the versions of the "new" scholars were often neither more nor less accurate than the medieval ones; and it is certainly legitimate to recognize, at least in certain cases, the superiority of formalistic logic evaluation. The indisputable fact remains, however, that in the schools set up by the major figures of humanistic culture, along with the study of poets and classical orators, the study of scientists and philosophers (whether we are speaking of Aristotle or Hippocrates, Galen or Pliny, Euclid or Ptolemy) never failed to be present. The reason is that the humanists always substantially concur when it comes to recognizing that the return to the great paradigms of classical cultures cannot be reduced solely to the first level of studying texts that are exemplary from stylistic and linguistic 


\section{4 / Renaissance and Reformation}

standpoints. Rather those cultures must be recovered as a whole whereby it becomes possible to acquire the fruits of over a thousand years of experience.

This is the reason why the writings of the scientists of Antiquity were now studied for the purpose of understanding them in their original structure, going back to the historical and linguistic conditions that produced them, and their genuine sources, beyond the medieval tradition which was not to be trusted, since too often it was based on "doubtful" intermediaries. For the humanists, the first reappropriation of the scientific and philosophical sources of Antiquity that Western culture had already enacted between the 11 th and 13 th centuries, under the determining double Arab and Byzantine influence, was not enough. It could hardly suffice for a knowledge of the past undoubtedly directed at acquiring new models of thought in every field of intellectual endeavour. So that it is comprehensible that there was a philological return to the "direct" documents of the scientific tradition and 'classical philosophy with its reference to the "native," antique nature of doctrines and texts corrupted by a long linguistic and historical "decadence"; and it is immediately linked to the search for a simple and "effective" method of thought, often emphasizing its direct adherence to the criterion of common experience. This is exactly why, if we may also be ironical about the "formal" poverty of humanistic logic thought, in contrast to the subtlety and acuteness of the late scholastic masters, it is not hard to recognize the importance of the process of "simplification" carried out by the humanists for the purpose of returning to the great themes of classical science, which were, however, treated with a critical eye, and increasing awareness of the historical limits of the antiqui themselves. Nor do I feel we can ignore that in Valla's approach the charge of barbarity directed at the scholastic scholars was meant to indicate the impotence of a logic which at this point was totally separated from the cognitiones reales. Valla was criticizing the inability to grasp the linguistic roots of many problems, which were turned into themes of metaphysical and theological speculation, when they had instead grown up on the more humble but vital terrain of natural experience or everyday knowledge.

In this sense, the reaction of the humanist scholars to scholastic methods and their decision to trace the documents essential to traditional knowledge back to their historical origins, is actually a turning point also in the history of western scientific thought. Just think that the core of that tradition, the "peripatetic" concepts entrusted to the corpus of the Aristotelian writings, was once more interpreted as the fruit of a long, continuing historical experience, which, at any rate, was supposed to have included the ever growing knowledge of those 
Hellenistic and Byzantine "commentators" who had been only partially known to the medieval schools and who now, on the contrary, were translated, read, and commented on more and more. Recalling, for example, the influence on not just philosophical but also scientific ideas exerted by the integral recovery of the Platonic corpus, the knowledge of a vast part of the neo-Platonic tradition, the resurfacing of the "hermetic" texts, and the reopening of the great debate on classical astronomic and astrological notions allows us to evaluate well how similar experiences not only broadened the field of "retrospective" knowledge of the origins of western learning, but also provided occasions for an increasingly radical revision of the very Weltanschauung which conditioned the development and decline of medieval science.

On the other hand, in order to clarify better the terms of humanistic intervention within the framework of scientific and logical learning, we must not ignore the fact that relations between scholastic science and the humanistic and philological disciplines were rather more complex than we usually think. In addition, there are numerous well-documented cases of an effective and fruitful exchange between the two cultures. We are all aware of the well-known relations between the Florentine circle of Coluccio Salutati and his disciples and scholastic scholars of great prestige such as Biagio Pelacani and Pietro degli Alboini of Mantua. ${ }^{2}$ And, correspondingly, it would be just as interesting to study the other humanist circles such as the Ferrarese school of Guarino from the same point of view.

Two particularly significant figures that well indicate the typical late 15th-century cultural situation are Giovanni Pico della Mirandola and Ermolao Barbaro. It is common knowledge that the young Pico della Mirandola, who grew up in the typical scholastic environment of the Universities of Padua and Pavia, was well acquainted with the great scholastic scholars whom he used to defend in dispute with the "literatissimus" Barbaro. Of greater interest is the fact that Pico had also wanted to learn the "capiunculae cavillique sophistarum et suisseticae quisquiliae quae calculationes vocantur," and he took great delight in applying them to subtle problems of physics. We also know that Barbaro, often remembered as the extreme advocate of "formal" and "ciceronian" humanism, had also composed serious quaestiones de intentione et remissione formarum and studied the "suisseticae calculationes." Nevertheless, perhaps the most obvious demonstration of the connection between the "studia humanitatis" and broad scientific and logical studies is offered by a master of rhetoric and translator of Aristotle's Poetica, Giorgio Valla. In his wide-ranging encyclopedia, De expetendis et fugiendis rebus (published posthumously in 1501), motifs of clear humanistic inspiration are linked to the knowledge of doctrines and tech- 


\section{6 / Renaissance and Reformation}

niques belonging to scholastic science and to the direct usage of several of the greatest documents of classical learning, above all Archimedes. But it is clear that the examples of such connection between humanistic behaviour and way of thinking (with the humanists' philological and critical interest) could easily be multiplied, as several figures worthy of greater attention from cultural historians (such as Galeotto Marzio, Girolamo Manfredi, and, generally speaking, the group of Bolognese humanists of the school of Urceo Codro) will prove.

Mention of Giorgio Valla might also be the best opportunity to tackle directly another subject which is exceedingly important from our particular outlook. I am speaking of the real contribution of the humanists to the return to the major documents of classical science in clearer translations and more complete, systematic forms. I do not, of course, intend to deny that the 13 th- and 14th-century scholastic world was already in possession of an invaluable body of knowledge and doctrines of classical origins acquired through a necessary, obvious mediation and great historical comparison with the other civilization. It is also obvious that the scholars of that period were already able to acquaint themselves with Aristotle, Galen, Euclid and Ptolemy, that they had quite an accurate grasp of important texts and documents regarding other aspects of science in Antiquity, and that they made excellent use of the Indian and Arabic mathematical discoveries and the new developments in optics and chemicae techniques. Yet it is just as indisputable that the humanists applied their philological methods, linguistic notions, and mainly their more mature historical sense, to present - in new forms and with different methods of comment - all the most important "sources" of the past, such as Galen, Hippocrates, Euclid, Erones, Pappus, Theones, Apollonius, Diophantus. They introduced to their contemporaries works that were previously unknown or else ignored in fields ranging from medicine, mechanics, and geography to mathematics and astronomy. Works that were already known were now made available in their original tongue. The works were discussed with real adherence to their historical nature and, most important, judged in a context of philosophic and scientific traditions which was much vaster than the context available to medieval interpreters. The history of the new editions, translations and commentaries published during the 15 th and 16th centuries by the scholars of humanist background could thus constitute an important chapter of a less limited and non-conformist history of Renaissance science. Moreover, Paul Lawrence Rose's recent work on the history of mathematics during the Italian Renaissance, to cite just one example, has already shown the results to be had from an in-depth survey. ${ }^{3}$ It is my feeling that studies of this type - naturally extended to the new methods of discussion of the same Arabic sources 
- would ease the way for future scholars of the history of other disciplines as well as for anyone truly anxious to understand the relations between the humanist scholars and the emerging class of specialists and artistae of such importance for Renaissance developments in scientific and technological learning. In this respect the results of a recent conference in Florence centred upon a discussion of Brunelleschi's scientific knowledge and his relations with the humanistic world are already quite encouraging. This is confirmation of what we already have acquired from the interpretations of another great personality of the 15 th century, the artist, writer, scientist and humanist Leon Battista Alberti, whose experience appears more and more to express the whole Italian cultural development of the century.

Indeed, only by reconstructing how these works circulated, reached certain circles, and were read or at least understood by writers, technicians, artists, and even merchants, can we really throw light upon many still unsolved problems and above all clear up the real complexity of circumstances and intellectual relations which have been too simplified in the sparring of opposing ideological evaluations. I have no intention of entering into details of mere erudition. Nevertheless, I think that it would be worthwhile to recall at least some of the exemplary events which show the historical value of humanistic intervention in returning to a number of basic problems of classical scientific thought. The vicissitudes of the Greek codex A of Archimede's Works which reached Italy in the 12th century, and has been preserved in the Papal library since 1226, are known and have already been studied. That it circulated in the 15 th century is also well known. But a precious clue to the humanists' approach to science can be obtained by noting that in 1450 this great source was in the hands of Lorenzo Valla. Then, in 1460, it was copied and translated into Latin by Jacopo Cremonese on behalf of the humanist pope, Nicholas V. Later it was again copied on behalf of Cardinal Bessarione, before new copies were transcribed in Rome in 1490 and in Florence in 1491 as a result of the efforts of the "grammatician" and "philologist" Poliziano. On the other hand, how can we forget Giorgio Valla's use of Archimedes' text in the codex which was then passed on to Alberto Pio III of Capri and which, in the opinion of Heiberg and Heat, is the starting point for the "Laurentianus" and "Parisiensis" that are fundamental for a reconstruction of the text? And likewise can we disregard the presence of an Archimedes in Paolo Dal Pozzo Toscanelli's library, right in the period when the relationship with Regiomontanus and Cusanus was extremely close? And there is more. It is also necessary to emphasize that humanistic culture did not only make the circulation of the Greek texts of classical scientists and the new translations of these texts easier and more widespread, but it 


\section{8 / Renaissance and Reformation}

also taught how to study and understand them as expressions of a civilization no longer identifiable with the absolute predominance of the "Philosophus." For the rediscovery and defense against the same Aristotelian criticism by the oldest Greek philosophi naturales, the renewed knowledge of Epicurus, Democritus and Lucretius implied a new interest in the atomistic concepts too, with consequences that will be clearly visible by the 16 th century. Likewise, the reawakened acquaintance with Plato, Plotinus, Proclus, and the neo-Platonists, which we have already referred to, contributed to create a great confrontation of doctrines, methods, and concepts of reality without which the growing questioning of traditional learning would have been impossible. Even the people who do not accept certain excessive insistences on the "hermetic" components of the astronomical revolution or the solar myths that were so dear to Ficino, Pico, and their followers cannot deny that Copernicus and Kepler undoubtedly were acquainted with these doctrines and made use of them in the context of strictly scientific works. Historians must also never forget that in order to challenge such an old and venerable concept of the world, so protected by the double defense of "official" philosophy and theology, a return to the "origins" was really necessary. It was essential to rediscover the various proposals which the very scholars of Antiquity had put forth, as well as to achieve full and complete understanding of all the contradictions which had grown up over the centuries about Ptolemy's machina mundi.

It is a highly important fact that right in Italy, in circles often open to specific humanistic influences, the studies on Ptolemy's text were so well received and tied in with the teaching of the astronomers Puerbach and Regiomontanus, who were responsible for many of the most important developments in 15 th-century astronomy. In this case, too, a humanistic edition (the Cosmographia) directed by a well-known Ferrarese astrologer, Pietro Bono Avogaro, with the participation of a number of outstanding Bolognese humanists such as Filippo Beroaldo, Girolamo Manfredi, and Cola Montano, offers numerous topics for a discussion which will go on for years and which belong to that long, complete process of the revision of the Ptolemaic doctrine up to the great Copernican revolution. And at this point I would like to call your attention to the introductory pages which - with eloquent moderation - praise the fruitful efforts of those who were finally able to restore the science of the classical astronomers to its genuine expression, thereby freeing it from all the deformations introduced "by the ignorance and daring of the past centuries." It is not surprising that similar words could also have great influence on scientists who, at the same time, were moving towards a critical recognition of classical learning, and discovering its various possible developments, along a line which differed from that of codified academic learning. 
Likewise I believe that the young Copernicus was fully aware of the profound significance of the method that the Bolognese teacher of Greek Urceo Codro (probably his professor) followed in explaining Aristotle's "physical" texts during his academic courses. Codro urged his disciples to go over all fields of knowledge from logics to astronomy, from the fundamentals of physica to the historia animalium and medicine, as links of a single chain. And the humanist used to repeat that "nothing is so shameful that it isn't more shameful to ignore it." These words perfectly express his free and critical way of thinking and his love for specific and accurate research which led him to read and comment on with philological expertise even the writings of classical philosophers and "physicists" using the same procedure that had already been experimented with in order to reconstruct other aspects and traditions of the world of Antiquity.

During the same period in nearby Ferrara another scholar, Niccolo Leoniceno, was working on the same writings of Galen. Leoniceno was attempting to throw light not only on the great doctor's actual concepts, but also on his methodological proposals which were often deformed and adulterated by the undue confusion among works whose intentions and ends differed. Making use of his knowledge of the greatest classical commentators such as Ammonius, Philoponus, Johannes Damascius, Alexander of Aphrodisia, the pseudo-Alcynoos, and Proclos, he laid emphasis upon the difference and the deep logical distinction among the three "ways" proposed by Galen in Ars Parva, the classical procedures of Aristotle's demonstration, and the four methodi dialectices typical of the Platonic doctrine. Thus, a work like the De tribus doctrinis ordinatis secundum Galeni sententiam holds its well-deserved place at the origin of a discussion destined to join doctors, philosophers, scientists, in a common search for the methodic tools needed to ensure quicker, easier, and more certain scientific learning and discovery.

However, if we attempt to single out other works that equally influenced the evolution of methods and logical approach to science between the end of the 15th and the beginning of the 16th century, we must consider not just the versions and comments of another master, also of Paduan background, Niccolo Leonico Tomeo, not only the specific translations by Ermolao Barbaro and Girolamo Donato, but, more generally, all the extensive proof of the growing presence of the graeci commentatores who were considered expressions of a single cultural line. Giamblicus, Porphirius, Alexander, Themistius, Simplicius and Philoponus are the names of the authors that the scholars with humanistic background offered up again, often in their original tongues, in order to change attitudes to problems of logics and peripatetic physics and "psychology," which could thus be tackled with such rich and original experiences. Whoever recalls the development that the Paduan school enjoyed during the whole Cinquecento and reflects on the his- 
torical function of well-known scholars such as Girolamo Capivacci, Bernardino Tomitano, and, especially, Jacopo Zabarella definitely has no doubts about the contribution of humanist philology to the internal transformation of the peripatetic tradition itself, increasingly more aware of its own theoretical roots and the extreme complexity of its own problematic field. Of course, it is always wise to point out the limits of 16th-century neo-Aristotelianism, which is sometimes taken -with excessive ease - to be one of the antecedents of the new Galilean methodology. Likewise it must be strongly emphasized that neoAristotelianism was incapable of actually applying the tools of mathematical knowledge to the comprehension of natural phenomena. Yet what Zabarella managed to do can hardly be dismissed as unimportant. With great clarity, he was able to establish the exact and rigorous order of the various peripatetic forms and methods of learning, their various functions and destinations, the insuperable difference between "science" and "opinion," and, lastly, the exquisitely dialectic-rhetorical nature of a broad section of the Aristotelian logical apparatus. These are the very motifs which also appear in Galileo's youthful writings, extremely concerned with analysis over method and logic which in the major Italian universities such as Pisa and Padua were highly developed at the time. And this entailed, I should like to add, aspects in common with a large part of the European philosophical culture of the 16th century which involved scholars and authors of different tendencies in fierce debate.

On the other hand, how can we neglect certain aspects of 16thcentury culture, which hint that the discussion over the logical nature of mathematical demonstration and its relations to the peripatetic apodictic laws was tied in with the radical renovation of mathematical science enacted under the influence of the great "return" of the major documents of Greek geometry and mechanics? It is well known that similar problems were debated in various cultural environments - for instance during the disputes between Ramus and Charpentier, and Ramus and Schegk. But, not to stray from the Paduan circle of Aristotelians of humanistic background, it should be recalled that while Alessandro Piccolomini maintained a sharp distinction between logical and mathematical procedures, by 1556 , in Venice, a Paduan professor of logics and mathematics, Pietro Catena, had collected and commented on all of Aristotle's texts on logic concerning demonstration and mathematical methods, and Francesco Barozzi, another scholar from the same school, affirmed the "certainty" of mathematics. Actually discussions like these, whatever their purpose and outcome, show that many 16 thcentury intellectuals (all of whom had been through humanistic schools and studies) were already becoming more and more aware of the special character of the mathematical technique of scientific learning, which by 
now was detached from the traditional fabric of scholastic learning. And it is symptomatic that, just about the same time, even the "technicians" and "artists," who were so often close to humanistic circles or else linked by social relations or friendship to scholars of humanae litterae, began to get involved in these problems - or, at least, they felt the very same need to refer to the prime sources of their learning and return to discussions of fundamental works and their authors.

Undoubtedly, these "practical" men, driven by the concrete interests of their jobs and the new needs of productive life, had cultural backgrounds and mental outlooks that ranged far from the humanists' and likewise had little to do with the ways and traditions of the university masters. It is hardly erroneous to stress the operative nature of their studies, which never lost sight of the terra firma of real-life experience and whose purpose was to achieve the specific verification of physical facts and relationships. But is is hard to deny that their strong thrust, both empirically and pragmatically, which was linked to the interests and curiosity of the new emerging social classes, found a fruitful and positive outlet only when it met up with the new critical methods, with the result of a radical change of mind about classical and medieval science. In other words, the same "technicians" were soon aware that it was impossible to solve the new problems posed by the social and civil development of the period without the aid of systematic meditated reflections, using the theoretical and practical tools provided by a culture that had greatly enriched understanding of the past and also supplied examples of alternate concepts to those dominant in the late medieval scholastic world. These homini sanza littere were the ones who got involved in ventures which within the defined framework of scientific learning had the same significance as the work of critical revision already conducted by the humanists in philosophical, historical and, lastly, theological culture. That is why historians of science should evaluate the interest of the practical mathematicians and "artists" in humanist texts and translations as well as their interest in medieval mathematicians ranging from Giordanus Nemorarius and Levi ben Gerson.

The inventory of the books in Leonardo's collection has already offered and continues to offer a chance to meditate upon the complexity of interests and curiosities which led a "technician" to read works which we certainly could not remove from the influence of humanist traditions, and find in his manuscripts so many suggestions and memories of them. A text as widely read as the Summa by Leonardo's friend Luca Pacioli confirms the extreme receptiveness of a practical mathematician to philosophical Platonic ideas that surely had ripened neither at the counters where he did his trading nor during the meditations of an isolated retreat. In this case too, however, more than the actual value of 
the single notions, I feel that it is the slow but resolute acquisition of a new way of thinking which should be of interest to the historian. This new way of thinking admittedly developed from the need for urgent practical applications. But it was supported, at any rate, by the humanistic return to the classics - and by classics I mean the works of Archimedes, Diophantus, Pappus, Heron, who, not by chance, were so translated and commented on, with a method capable of establishing a critical relationship with the Greek, Arabic, and medieval mathematicians' documents themselves. The work of editors such as Maurolico and Commandino might have had, from this standpoint, even greater historical importance than the brilliant studies of Cardano or Tartaglia, who were so often involved in playing a subtle and difficult intellectual game. And yet, Tartaglia might very well represent the high point of a process of cultural transformation which at this point is bound to reestablish - on premises of a critical nature - the connection between the pure exercising of the "art" of mathematics and the comprehension of the basic problem of a whole field of intellectual research.

The author who perhaps most enthralls the technicians and "artists" of the Cinquecento is this translator of Euclid and Archimedes. In his General trattato di numeri e misure, Tartaglia acts as an erudite propagator of the mathematical learning of his time; he is also the author of Quesiti et inventioni diversi, in which he treats specific technical problems relating to the art of war, such as ballistics, fortification engineering, building science, and topographical surveying. Even though Tartaglia in the last book describes studies which are of a purely algebraic and geometric nature, all of his other books are proof of his approach as a "technical" scientist who, nevertheless, just like Maurolico and Commandino, has learned from a return to the classics the proper way of a methodic analysis according to the principles suggested by "art, measure, reasons."

It is thus hardly surprising that Tartaglia's school produced some of the best qualified and most brilliant mathematicians and scholars who, with newborn critical commitment and an increasingly wider and freer knowledge of the classical texts, were even able to tackle the problems in mechanics which had undergone early development in late scholastic "physics." And it is not at all accidental that two of Tartaglia's pupils, Ostilio Ricci and Giovambattista Benedetti, even influenced and, under many aspects, critically, the scientific formation of the young Galilei. But Benedetti, just like Maurolico, Commandino, De Monte and Tartaglia himself, all call our attention to another theme of fundamental importance to the development of scientific learning, and a theme which is also hard to treat without a "philological" type of mediation. I am alluding to the growing interest in applied geometry, the methodic 
principle of classical statics, whose principles were applied more and more systematically even to problems of mechanics. Under the determining influence of Archimedes, whose works provided a strong boost to new observations and studies, the theory of local motion was truly transformed into a chapter of applied geometry, removing it once and for all from metaphysical influences. And even the very theories of the medieval scholars were again discussed and delved into by men who were well acquainted with Archimedes, Euclid, Diophantus and Pappus, and who attributed a methodic significance and rigorous critical measure to their studies. Thus Benedetti, basing himself on the essential principles of Archimedes' statics, had already arrived at extremely interesting results both in the study of the gradually slowing down of violent motion and in the analysis of the acceleration of motion of the fall, setting forth considerations which appear to be a prelude to actually understanding the principle of inertia.

Naturally Benedetti, like many of the mathematicians and technicians of his day, was still far from a complete methodic definition of dynamics problems, undecided as he was between the application of the exact method of analysis of geometric proportion to problems in dynamics, and resorting to concepts like "impetus" whose philosophical origin is well-known. Still, aside from all the limits - typical, of course, of a whole cultural and historical situation - similar developments provide the historians with important elements for evaluating the actual roots of a rapid theoretical development which would shortly change the very fundamentals of the scientific method and the approach to problems of the knowledge of nature.

The new developments of the "16-century philosophy of nature"which all bear signs, though to different degrees, of humanist influence - did of course contribute to the change. Obviously, I have no intention of entering into a discussion here of the numerous problems connected with an historical evaluation of the works of Bernardino Telesio, Giordano Bruno, Tommaso Campanella and other Italian and European authors whom their contemporaries often labelled "novatores." Likewise, it is impossible for me to take up the old dispute over their affinity to or divergence from the new models of learning. The opinions of scholars differ and contrast so widely on this point first of all with regard to the humanist "affinities" of those authors and secondly regarding their rank in the "pre-history" of modern science that great prudence and caution must be used. But once this criterion has been clearly stated, we can nevertheless recognize that even the works of the "novatores" represent an indisputable and necessary moment in the general intellectual "reform" from which our science was born. Certainly we could go into the still "archatic" nature of 
Telesio's reflection, his so frequent reference to the pre-Socratic traditions versus the Aristotelian auctoritas. We could talk about Bruno's imaginative, fantastic, "baroque" cosmic vision that strays so far from the mathematic rigor of the new science; and speaking of Campanella it would not be very hard to pick out the deep magical and astrological component running through his doctrines. Nevertheless, I am convinced that a better-versed, more organic historiography will be able to find proof of their contribution to the advent of a "spirit" capable of transforming its discoveries and inventions into guiding principles of human learning and behaviour. It is true that this need and assertion were still locked inside of thoughts rich in clever intuitions but poor in rigorous methodic capacity, open to daring plans for great renovations, but still far from the "humble" and "patient" exercise of science. Yet, if Galileo, by the beginning of the 17 th century, was able to take on an historical value that surpassed the indisputable validity of his methodic procedures, this was because two centuries of humanist education and criticism had radically modernized the ways of thinking, the attitude towards tradition, and the very approach to the documents of classical learning, by this time the subject of refined historical evaluation and philological study. Moreover it is indeed worthy of mention that even Galileo had received a humanistic type of education, had lived in an environment which was open even to artistic and literary controversy, and had from the time of his apprenticeship appreciated the labours of the editors, translators, and commentators of the classics of the science of Antiquity.

Only in a culture as rich and varied as the one in which the Pisan astronomer grew up could the fruits of a searing intellectual labour that had not left unchanged a single domain of human learning and reflection be truly gathered. And that Galileo, upon this foundation, was able to enact a methodological revolution whose consequences reached so far and so deep is, in my opinion, the most persuasive confirmation of the humanistic culture's contribution to the birth of the "new science."

\section{University of Florence}

Notes

$1 \mathrm{P}$. Duhem, Études sur Léonard de Vinci. Ce qu'il a lu et ceux qui l'ont lu, Paris, 1906-1913; Id., Le système du monde, VII, Paris, 1956, pp. 3 ss; X, Paris, 1959, pp. 369-376; L. Thorndike, A History of Magic and Experimental Science, IV, New York, 1934, pp. 386 ss.; G. Sarton, Introduction to the History of Science, Baltimore, 1947, IIl, P.I., pp. 13-15; J.H. Randall, Jr. "The Development of Scientific Method in the School of Padua," Journal of the History of Ideas, I (1940), 177-206; Id., "Paduan Aristotelism: An Appraisal," Aristotelismo padovano e filosofia aristotelica: Atti del XII Congresso internazionale di Filosofia, Firenze, 
1960, pp. 139 ss.; Id., The School of Padua and the Emergence of Modern Science, Padova, 1961 (and s. N.W. Gilbert, "Galileo and the School of Padua," Journal of History of Philosophy, 1 (1963), 223-31); A. Maier, Die Vorläufer Galileis in I4. Jahrhundert. Studien zur Naturphilosophie der Spätscholastik, Roma, 1949; Id., Zwei Grundprobleme der Scholastischen Naturphilosophie. Das Problem der intensiven Grösse, Die Impetustheorie, Roma, $1951^{2}$; Id. I An der Grenze von Scholastik und Naturwissenschaft. Die Struktur der materiellen Substanz. Das Problem der Gravitation. Die Mathematik der Formlatituden, Roma, 1952 2; Id., Zwischen Philosophie und Mechanik. Studien zur Naturphilosophie der Spätscholastik, Roma, 1958.

2 C. Dionisotti, "Ermolao Barbaro e la fortuna di Suisseth, Medioevo e Rinascimento: Studi in onore di B. Nardi, Firenze, 1955, I, pp. 218-53; "Gli atti ufficiali dello Studio fiorentino dal maggio al settembre 1388," a cura di R. Abbondanza, Archivio storico italiano, 117 (1959), 80-110; E. Garin, "La cultura fiorentina nella seconda metà del 300 e ii "barbari britanni,", L'Età nuova, Napoli, 1969, pp. 139-77; C. Vasoli, "Pietro degli Alboini da Mantova "scolastico" della fine del Trecento e un'epistola di Coluccio Salutati," Studi sulla cultura del Rinascimento, Manduria, 1968, pp. 11-39.

3 P.L. Rose, The Italian Renaissance of Mathematics: Studies on Humanists and Mathematicians from Petrarch to Galileo, Genève, 1976.

4 Archimedis Opera omnia, ed. I.L. Heiberg, Leipzig, 1880-81; n.e., 1910-13-15, repr. 1972, Prolegomena (cfr. E.J. Dijksterhuis, Archimedes, Copenhagen, 1956, pp. 34-49); The Works of Archimedes, tr. T.L. Heath, Oxford, 1897-1912, Introduction, ch. II, "Manuscripts and precedent editions," pp. XXIII-XXXVIII; and J.L. Heiberg, Beiträge zur Geschichte Georg Valla's und seine Bibliothek, Leipzig, 1896. 